\title{
Phenolic profile and bioactivity of cardoon (Cynara cardunculus L.) inflorescence parts: Selecting the best genotype for food applications
}

\author{
Maria Inês Dias $^{\mathrm{a}}$, Lillian Barros ${ }^{\mathrm{a}}$, João C.M. Barreira ${ }^{\mathrm{a}}$, Maria José Alves ${ }^{\mathrm{a}}$, Paulo Barracosa ${ }^{\mathrm{b}, \mathrm{c}}$, \\ Isabel C.F.R. Ferreira, ${ }^{\mathrm{a}, *}$ \\ a Centro de Investigação de Montanha (CIMO), Instituto Politécnico de Bragança, Campus de Santa Apolónia, 5300-253 Bragança, Portugal \\ ${ }^{\mathrm{b}}$ Escola Superior Agrária de Viseu, Instituto Politécnico de Viseu, Portugal \\ ${ }^{\mathrm{c}}$ Centro de Investigação e de Tecnologias Agroambientais e Biológicas (CITAV), Universidade de Trás-os-Montes e Alto Douro, Quinta de Prados, 5001-801 Vila Real, \\ Portugal
}

\section{A R T I C L E I N F O}

\section{Keywords:}

Cynara cardunculus L.

Phenolic composition

LC-DAD-ESI/MSn

Antioxidant activity

Antibacterial activity

\begin{abstract}
A B S T R A C T
This study was designed to characterize the phenolic profile and bioactivity of hydroalcoholic extracts from different cardoon (Cynara cardunculus L.) genotypes. The analytical work focussed on the inflorescence stigmas, owing to their application in cheese production. Nevertheless, other parts were concomitantly analysed aiming to define their possible use in related applications. Phenolic profiles obtained by LC-DAD-ESI/MSn showed significant differences among different cardoon genotypes, but apigenin and caffeoylquinic acid derivatives were generally the major molecules in all samples. Genotype influence has also been observed in relation to the antioxidant and antibacterial activities. Besides their strong antioxidant activity, the cardoon inflorescences showed satisfactory antibacterial activity, namely against Gram-positive strains, with particularly low MIC in Listeria monocytogenes. Overall, it was possible to identify the cardoon genotype (within the selected ones) providing the best standardized ingredient (stigma) with considerable added-value to be included in the process of cheese making.
\end{abstract}

\section{Introduction}

Cynara cardunculus L. belongs to the Asteraceae Dumortier family and is native to the Mediterranean Basin. It includes three botanical taxa: the globe artichoke (var. scolymus L.), the cultivated cardoon (var. altilis DC) and the wild cardoon [var. sylvestris (Lamk) Fiori]. Being a cross-pollinated diploid species $(2 n=2 \times=34)$ with proterandrous and asynchronous sexual maturity, $C$. cardunculus possesses a highly heterozygous genetic background (Basnizki \& Zohary, 1994; Portis, Barchi, Acquadro, Macua, \& Lanteri, 2005; Scaglione et al., 2009). Artichoke leaves have been traditionally employed for their diuretic, hepatoprotector and cholagogue effect, also presenting some choleretic and antidiabetic activity (Lattanzio, Kroon, Linsalata, \& Cardinali, 2009; Rodriguez, Giménez, \& Vázquez, 2002). In addition, the aqueous extracts of cardoon inflorescence have been used for centuries (particularly in Mediterranean regions) as coagulants in traditional ewes' milk cheese making, providing distinctive characteristics of texture and flavour. In fact, and according to specific regulation, using aqueous extracts from cardoon inflorescences (Cynara spp.) as a coagulant is obligatory (Roseiro et al., 2005) in the manufacture of several traditional ewes' milk cheeses. Some well-known examples are represented by highly-valued Portuguese cheeses, such as "Serra da Estrela", "Castelo Branco", "Azeitão", "Évora", "Niza" and "Serpa", in which the cardoon inflorescences, specifically their stigma, are used for their high content in aspartic proteases and high milk-clotting activity (Veríssimo, Esteves, Faro, \& Pires, 1995). In the case of "Serra da Estrela" cheese, C. cardunculus has actually been recognized as a key factor in cheese authenticity, as defined in an integrated project (CARDOP) designed to promote the Protected Designation of Origin (PDO) (Barracosa, Oliveira, Barros, \& Pires, 2018).

In addition to their primary proteolytic effect, wild and cultivated forms of $C$. cardunculus could also be valued for their phenolic compounds with bioactive properties, particularly in their stigma. The high content of phenolic acids (mainly mono and dicaffeoylquinic acids) and flavonoids (apigenin and luteolin derivatives) deserve to be highlighted. In fact, these compounds have been extensively studied in different extracts of selected cardoon parts, belonging to different genotypes (Colantuono, Ferracane, \& Vitaglione, 2018; Fratianni, Tucci, Palma, Pepe, \& Nazzaro, 2007; Garbetta et al., 2014; Gouveia \& Castilho, 2012; Kukić et al., 2008; Lombardo et al., 2010; Maietta et al.,

\footnotetext{
* Corresponding author.

E-mail address: iferreira@ipb.pt (I.C.F.R. Ferreira).
} 
2017; Nouraei, Rahimmalek, \& Saeidi, 2018; Pandino, Lombardo, Mauromicale, \& Williamson, 2011b; Pandino, Lombardo, \& Mauromicale, 2013; Pandino, Lombardo, Mauromicale, \& Williamson, 2011a; Petropoulos et al., 2016; Pistón et al., 2014; Ramos et al., 2014).

The bioactivity of cardoon has also been reported on several occasions, for example the antioxidant potential of artichoke (Garbetta et al., 2014; Gouveia \& Castilho, 2012; Kukić et al., 2008; Pandino et al., 2011a; Petropoulos et al., 2016; Pistón et al., 2014; Ramos et al., 2014; Valentão et al., 2002), or the antibacterial activity of its alcoholic and aqueous preparations against ATCC strains Kukić et al. (2008).

The full characterization of the phenolic compounds and bioactive properties of cardoon is very important to validate the use of its inflorescences in dairy products, providing health-promoting properties, besides its potential use as an authenticity marker of cheese. Therefore, the main objective of the present study was to characterize the phenolic composition (non-anthocyanin and anthocyanin compounds) of inflorescences from three selected genotypes established in "Serra da Estrela" region: 'F1-25-4' (genotype: var. sylvestris), '3M' (genotype: var. altilis), and '5M' (genotype: var. altilis). Furthermore, the antioxidant and antibacterial properties of methanol/water $(80: 20, v / v)$ extracts obtained from these samples were evaluated.

\section{Material and methods}

\subsection{Samples}

The inflorescences of the selected genotypes, F1-25-4' (var. sylvestris), '3M' (var. altilis), and ' $5 \mathrm{M}$ ' (var. altilis) were individually picked in the Serra da Estrela region (Viseu- Portugal) $\left(40^{\circ} 42^{\prime} 17.5^{\prime \prime} \mathrm{N}\right.$, $7^{\circ} 54^{\prime} 45.8^{\prime \prime} \mathrm{W}$ ) during June-July of 2016 , separated and placed in dark and dry conditions until further analysis (Fig. 1a). Inflorescence preparation was organized at the School of Agriculture of Viseu. Plants were maintained in a genetic resources field at the School of Agriculture of Viseu, and the species identification was performed by the initial collector (Paulo Barracosa). For each genotype, a voucher was prepared and samples were stored in the Herbarium of the School of Agriculture of Viseu (HESAV).

A total of eight different samples of cardoon dried inflorescences were studied (Fig. 1b). The vegetal tissue was harvested following the same procedures employed by artisanal cheese producers. Considering its application in cheese production, the stigma represented the inflorescence tissue with highest interest to the present study, as it was aimed to define a high quality standardized ingredient for artisanal cheese production. Four different samples were considered: C2 ('F1-254'), C4, C5 (both from ' 3 M' genotype, but from different years) and C6 ('5 M'). In addition, other inflorescence parts were studied for comparison purposes: complete inflorescence (C1) and corolla (C3) of 'F125-4' genotype, purple epidermal papillae (C7) and the fibrous white inner part (C8) of ' $5 \mathrm{M}$ ' genotype. In this last case, the purple epidermal papillae accounted for $95 \%$, while the inner part with vascular bundles and transmitting tissue represented only $5 \%$. All samples were reduced to a fine dried powder ( 20 mesh), mixed to obtain homogenate samples and stored at $-20^{\circ} \mathrm{C}$ (to prevent degradation of compounds) until further analysis.

\subsection{Analysis of phenolic compounds}

The phenolic profile was determined by LC-DAD-ESI/MSn (Dionex Ultimate 3000 UPLC, Thermo Scientific, San Jose, CA, USA).

Non-anthocyanin compounds: Each sample $(1 \mathrm{~g})$ was subjected to a maceration extraction $\left(150 \mathrm{rpm}, 25^{\circ} \mathrm{C}\right)$ with methanol/water $(80: 20, v$ / $v ; 30 \mathrm{ml}$ ) for $1 \mathrm{~h}$, followed by filtration (Whatman filter paper No. 4). Afterwards, the residue was extracted with an additional portion of $30 \mathrm{ml}$ of methanol/water $(80: 20, v / v ; 30 \mathrm{ml})$, and the combined extracts were evaporated under reduced pressure (rotary evaporator Büchi R210, Flawil, Switzerland), to remove methanol, and then lyophilized
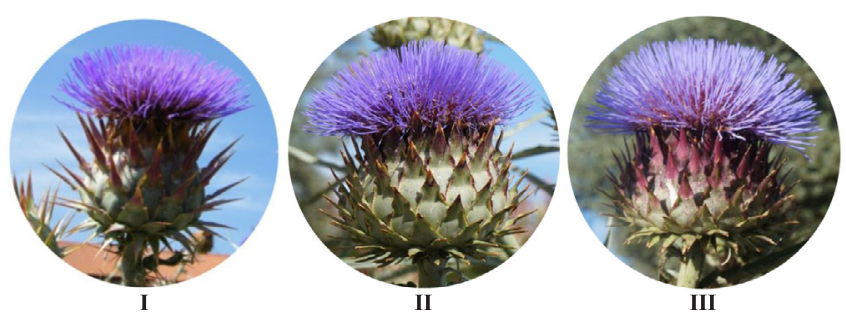

(a)

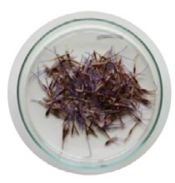

C1

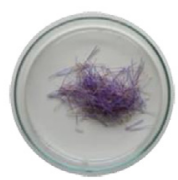

C2

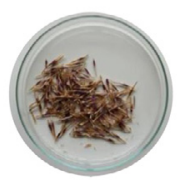

C3

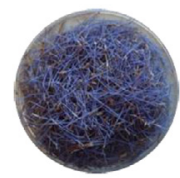

C4

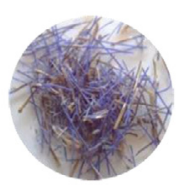

C6

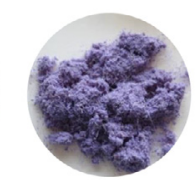

C7

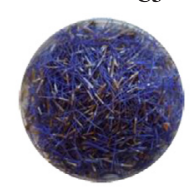

C5

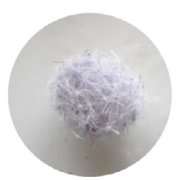

C8
Fig. 1. Botanical characterization of Cynara cardunculus genotypes. (a) Inflorescences of different cardoon genotypes 'F1-25-4' (I), '3M' (II) and 5M' (III). (b) Different analysed cardoon samples: inflorescence (C1), stigma (C2), and corolla (C3) of 'F1-25-4' genotype; stigma from genotype '3M' collected in 2014 (C4) and 2015 (C5); stigma (C6), purple epidermal papillae (C7), and fibrous white inner part (C8) of '5M' genotype.

(LabConco, Frezone, Kansas, MO, USA) to obtain a dry extract.

These compounds were separated and identified as previously described by Bessada, Barreira, Barros, Ferreira, \& Oliveira (2016). The obtained extracts were re-dissolved at a concentration of $5 \mathrm{mg} / \mathrm{ml}$ with methanol/water $(80: 20, v / v)$. Detection of compounds was performed using a DAD (280, 330 and $370 \mathrm{~nm}$ as preferred wavelengths) and a Linear Ion Trap LTQ XL mass spectrometer equipped with an ESI source (Thermo Finnigan, San Jose, CA, USA) working in negative mode.

Anthocyanin compounds: Each sample (1 g) was extracted during a $1 \mathrm{~h}$ maceration, with $30 \mathrm{ml}$ of methanol/water $(80: 20, v / v)$ containing $0.1 \%$ citric buffer $(1 \mu \mathrm{M})$. After filtration (Whatman No. 4 paper), the residue was re-extracted with $30 \mathrm{ml}$ of methanol/water $(80: 20, v / v)$ acidified with $0.1 \%$ citric buffer. In order to remove methanol, the combined extracts were evaporated at $35^{\circ} \mathrm{C}$, under reduced pressure, and further lyophilized. Extracts were re-dissolved at a concentration of $5 \mathrm{mg} / \mathrm{ml}$ in $80 \%$ acidified methanol with citric buffer $(0.1 \%)$. The anthocyanins present in the extract were separated and identified as previously described by Gonçalves et al. (2017). Detection of compounds was performed at $520 \mathrm{~nm}$, as the preferred DAD wavelength, in the MS equipment described above, working in positive mode.

Phenolic compounds (non-anthocyanin and anthocyanin) were identified based on the chromatographic behaviour, UV-vis and mass spectra, and data reported in the literature. Quantitative analysis was performed using calibration curves based on the UV-Vis signal of each available phenolic standard (Extrasynthèse, Genay, France): (A) gallic acid $\left(y=214168 x+27102, R^{2}=0.9999\right) ; \quad$ (B) chlorogenic acid $\left(y=168823 x-161172, \quad R^{2}=0.999\right) ; \quad$ (C) $p$-coumaric acid $\left(y=301950 x+6966.7, \quad R^{2}=0.999\right) ; \quad(D)$ apigenin-7-O-glucoside $\left(y=10683 x-45794, \quad R^{2}=0.991\right) ; \quad$ (E) naringenin 
$\left(y=18433 x+78903, \quad R^{2}=0.9998\right) ; \quad(F) \quad$ cyanidin-3-O-glucoside $\left(y=243287 x-1 \mathrm{E}+06, R^{2}=0.9953\right)$. The results were expressed as $\mathrm{mg} / \mathrm{g}$ of dry extract.

\subsection{Evaluation of bioactive properties}

\subsubsection{Antioxidant activity}

The methanol/water extracts described above were re-dissolved in $80 \%$ methanol in order to obtain a stock solution of $10 \mathrm{mg} / \mathrm{ml}$, which was further diluted to obtain a range of working concentrations to evaluate the antioxidant activity. 2,2-Diphenyl-1-picrylhydrazyl (DPPH, from Alfa Aesar, Ward Hill, MA, USA) radical-scavenging activity and reducing power assays were performed according to the protocol described by Barros et al. (2013). The final results were expressed as the concentration providing $50 \%$ of activity $\left(\mathrm{EC}_{50}\right)$ values $(\mathrm{mg} / \mathrm{ml})$ and Trolox was used as a positive control.

\subsubsection{Antibacterial activity}

The antibacterial activity was determined in the methanol/water (80:20, $v / v)$ extracts, which were re-dissolved in water in order to obtain a stock solution of $100 \mathrm{mg} / \mathrm{ml}$, and then subjected to further dilutions. The protocol for antibacterial assays was previously described by Dias et al. (2016), using clinical isolates from hospitalized patients that consisted of six Gram-negative bacteria (Escherichia coli, E. coli ESBL (extended spectrum of beta-lactamase), Klebsiella pneumoniae, $K$. pneumoniae ESBL, Morganella morganii, and Pseudomonas aeruginosa isolated from urine and expectoration) and four Gram-positive bacteria (MRSA- methicillin-resistant Staphylococcus aureus, MSSA - methicillinsensitive Staphylococcus aureus, Enterococcus faecalis and Listeria monocytogenes). Minimum inhibitory concentrations (MICs) were determined following the methodology proposed by Kuete et al. (2011a,b) with some modifications. The antibiotic susceptibility profile of the bacteria was also described by Dias et al. (2016). The concentrations of antibiotics applied are presented as Supplementary material.

Supplementary data associated with this article can be found, in the online version, at https://doi.org/10.1016/j.foodchem.2018.06.081.

\subsection{Statistical analysis}

Three independent samples were used and all the assays were carried out in triplicate. Data (except for MIC values) were expressed as mean \pm standard deviation (the number of significant numbers was maintained according to the standard deviation magnitude).

Linear discriminant analysis (LDA) was used to identify the most distinctive phenolic compounds and antioxidant parameters in each studied cardoon inflorescence sample. The stepwise technique was applied, based on the Wilks' $\Lambda$ test for variable selection ( $F$ to enter: 3.84; $F$ to be removed: 2.71 ). Only variables with a statistically significant classification performance $(p<0.050)$ were selected by the discriminant models. A leaving-one-out cross validation procedure was carried out to assess the model performance.

All statistical tests (SPSS Statistics for Windows version 23.0, IBM Corp., Armonk, NY, USA) were performed considering a 5\% significance level.

\section{Results and discussion}

\subsection{Phenolic compounds}

Table 1 presents the peak characteristics (retention time, wavelength of maximum absorption and mass spectral data), tentative identification and quantification of the non-anthocyanin and anthocyanin phenolic compounds detected in the extracts of $C$. cardunculus. An exemplificative (C5 sample) phenolic profile recorded at 280, 370 and $520 \mathrm{~nm}$ is shown in Fig. 2.

A total of sixteen phenolic compounds: six phenolic acids (peaks 1 , 2, 3, 4, 7 and 11), nine non-anthocyanin flavonoids (peaks 5, 6, 8, 9, 10, $12,13,14$ and 15) and one anthocyanin (peak 16) were identified in $C$. cardunculus. Flavonoids were the major family of compounds, mainly apigenin, luteolin and eriodictyol derivatives, which is in accordance with the review by Lattanzio et al. (2009). Peaks 5, 8, 9, 10, and 14 were identified as luteolin derivatives, presenting pseudomolecular ions $[\mathrm{M}-\mathrm{H}]^{-}$at $m / z 623,593,461,447$, and 533, respectively, and being identified as luteolin- $O$-hexoside- $O$-glucuronide (MS ${ }^{2}$ units at $\mathrm{m} / \mathrm{z} 461$ and 285), luteolin-7-O-rutinoside, luteolin-7-O-glucuronide and

Table 1

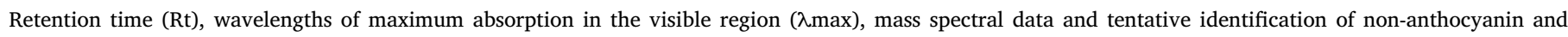
anthocyanin phenolic compounds in Cynara cardunculus L. samples.

\begin{tabular}{|c|c|c|c|c|c|c|}
\hline Peak & Rt (min) & $\begin{array}{l}\lambda_{\max } \\
(\mathrm{nm})\end{array}$ & $\begin{array}{l}\text { Molecular ion [M- } \\
\mathrm{H}^{-}(m / z)\end{array}$ & $\mathrm{MS}^{2}(m / z)$ & Tentative identification & References used for identification \\
\hline \multicolumn{7}{|c|}{ Non-anthocyanin phenolic compounds } \\
\hline 1 & 4.45 & 272 & 169 & $113(100)$ & Gallic acid & $\mathrm{DAD} / \mathrm{MS}$ \\
\hline 2 & 6.56 & 325 & 353 & 191(100),179(5),161(3),135(3) & 5-O-Caffeoylquinic acid & $\begin{array}{l}\text { Gouveia and Castilho, (2012)' } \\
\text { Petropoulos et al. (2016) }\end{array}$ \\
\hline 3 & 9.74 & 328 & 515 & $353(100), 335(38), 191(2), 179(18), 173(2), 135(4)$ & 1,3-O-Dicaffeoylquinic acid & Gouveia and Castilho (2012) \\
\hline 4 & 10.35 & 312 & 337 & $191(2), 163(100), 145(2), 119(5)$ & 3-p-Coumarouylquinic acid & Pistón et al. (2014) \\
\hline 5 & 12.37 & 345 & 623 & $461(100), 285(27)$ & $\begin{array}{l}\text { Luteolin- } O \text {-hexoside- } O \text { - } \\
\text { glucuronide }\end{array}$ & $\begin{array}{l}\text { Pereira, Barros, Carvalho, Santos- } \\
\text { Buelga and Ferreira (2015) }\end{array}$ \\
\hline 6 & 15.23 & $\begin{array}{l}284 / \\
\operatorname{sh} 322\end{array}$ & 463 & $287(100)$ & Eriodictyol-O-glucuronide & $\begin{array}{l}\text { Petropoulos, Pereira, Barros and } \\
\text { Ferreira (2017) }\end{array}$ \\
\hline 7 & 16.17 & 322 & 515 & $353(61), 335(4), 191(20), 179(4), 161(2), 135(2)$ & 1,5-O-Dicaffeoylquinic acid & Gouveia and Castilho (2012) \\
\hline 8 & 17.25 & 348 & 593 & $285(100)$ & Luteolin-7-O-rutinoside & $\begin{array}{l}\text { Gouveia and Castilho (2012), Pistón } \\
\text { et al. (2014) }\end{array}$ \\
\hline 9 & 17.68 & 347 & 461 & 285(100) & Luteolin-7-O-glucuronide & Gouveia and Castilho (2012) \\
\hline 10 & 18.22 & 345 & 447 & $285(100)$ & Luteolin-7-O-glucoside & Pereira et al. (2016) \\
\hline 11 & 19.51 & 328 & 515 & $353(100), 335(6), 191(5), 179(3), 173(2), 161(2), 135(2)$ & 3,5-O-Dicaffeoylquinic acid & $\begin{array}{l}\text { Gouveia and Castilho (2012), } \\
\text { Petropoulos et al. (2016) }\end{array}$ \\
\hline 12 & 20.67 & 337 & 577 & $269(100)$ & Apigenin-7-O-rutinoside & Gouveia and Castilho (2012) \\
\hline 13 & 21.68 & 337 & 445 & $269(100)$ & Apigenin-7-O-glucuronide & $\begin{array}{l}\text { Gouveia and Castilho (2012), } \\
\text { Petropoulos et al. (2016) }\end{array}$ \\
\hline 14 & 22.63 & 343 & 533 & $489(100), 285(30)$ & Luteolin- $O$-malonylhexoside & Pistón et al. (2014) \\
\hline 15 & 26.88 & 326 & 473 & $269(100)$ & Apigenin- $O$-acetylhexoside & Dias et al. (2013) \\
\hline \multicolumn{7}{|c|}{ Anthocyanin phenolic compounds } \\
\hline 16 & 31.21 & 5.16 & 535 & 491(6),449(5),287(1 00$)$ & Cyanidin-malonyl-hexoside $^{\mathrm{F}}$ & Lattanzio et al. (2009) \\
\hline
\end{tabular}




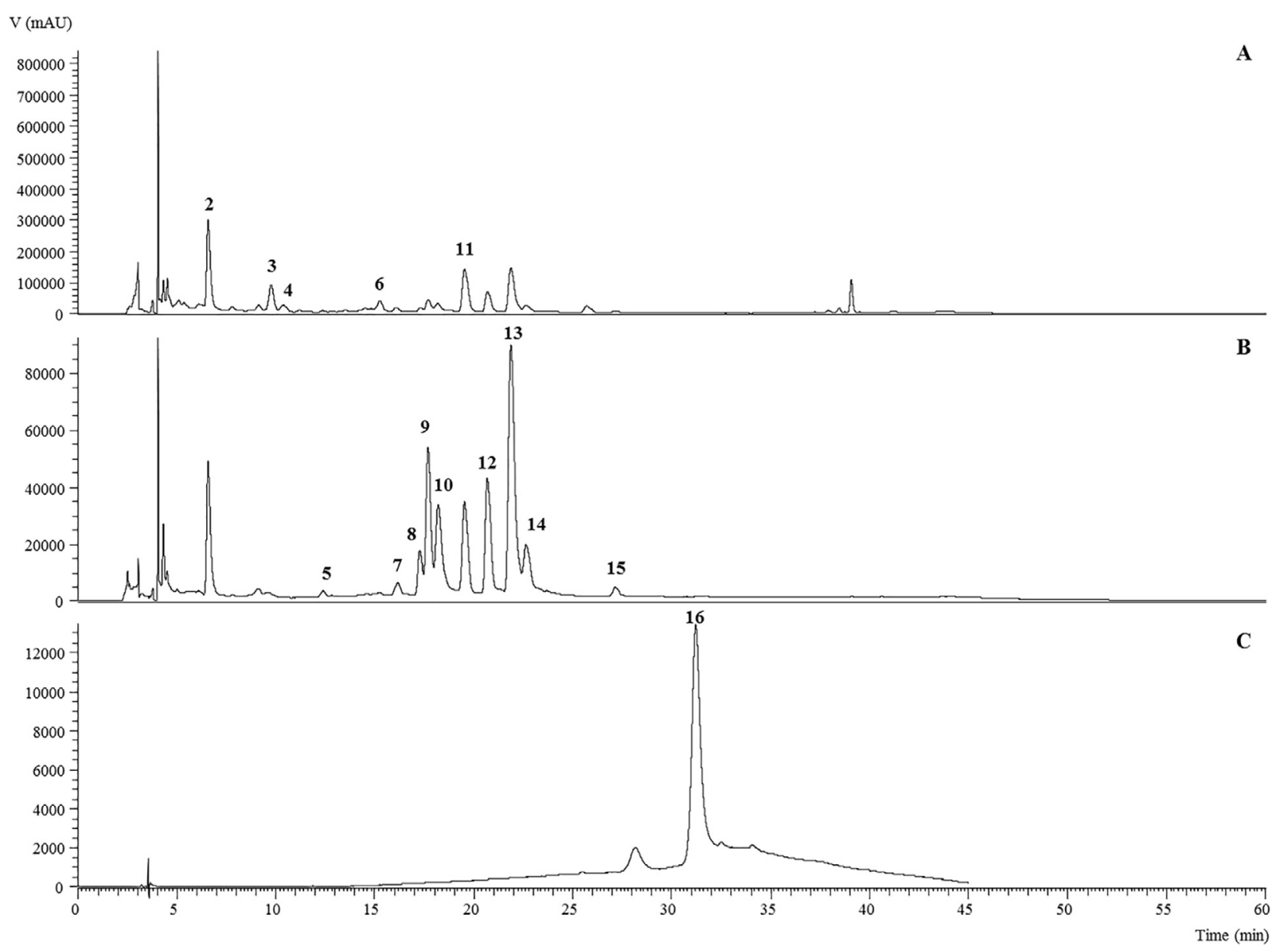

Fig. 2. Phenolic profile of C5 sample recorded at $280 \mathrm{~nm}$ (A), $370 \mathrm{~nm}$ (B) and $520 \mathrm{~nm}$ (C). Peak numbering is indicated as defined as in Table 1.

luteolin-7-O-glucoside (all with $\mathrm{MS}^{2}$ units at $\mathrm{m} / \mathrm{z} 285$ ), and luteolin- $O$ malonylhexoside (MS ${ }^{2}$ units at $m / z 489$ and 285), respectively. Peaks 12,13 , and 15 presented a pseudomolecular ion $[\mathrm{M}-\mathrm{H}]^{-}$at $\mathrm{m} / z 577$, 445 , and 473 and a unique $\mathrm{MS}^{2}$ fragment at $\mathrm{m} / z 269$, corresponding to the loss of rutinosyl (apigenin-7-O-rutinoside), glucoronyl (apigenin-7$O$-glucuronide) and acetylhexosyl (apigenin- $O$-acetylhexoside) units, respectively. Peak $6\left([\mathrm{M}-\mathrm{H}]^{-}\right.$at $\left.m / z 463\right)$ released a unique $\mathrm{MS}^{2}$ unit at $\mathrm{m} / z 287(-176 \mu)$, corresponding to the loss of a glucoronyl unit, being tentatively identified as eriodictyol-O-glucuronide. Finally, peak 16 $\left([\mathrm{M}-\mathrm{H}]^{-}\right.$at $\left.m / z 535\right)$, was the only anthocyanin identified and presented three fragment ions at $m / z 491(-44 \mu), 449(-42 \mu)$ and 287 $(-162 \mu)$, corresponding to the loss of malonyl and hexosyl moieties, which suggests its identification as cyanidin-O-malonyl-hexoside. This information is coherent with Lattanzio et al. (2009), who reported that cyanidin derivatives, mainly as glycosides, were the major anthocyanin compounds found in cardoon.

Phenolic acids, particularly gallic acid, $p$-coumaric acid derivatives and chlorogenic acid derivatives, were quantified as the second major family of phenolic compounds. Peak 1 was positively identified as gallic acid by comparing its retention time, mass and UV-vis characteristics with the commercial standard. Peak $4\left([\mathrm{M}-\mathrm{H}]^{-} \mathrm{m} / \mathrm{z}\right.$ at 337$)$ was tentatively identified as 3-O-coumaroylquinic acid, due to the base peak at $m / z 163$, corresponding to $[p \text {-coumaric acid- } \mathrm{H}]^{-}$, accompanied by a weak fragment at $m / z 191$. This compound was also described by Pistón et al. (2014) in hydroalcoholic and aqueous preparations of artichoke leaves from Uruguay. Regarding caffeoylquinic acid derivatives, peak 2 ([M-H $]^{-}$at $m / z$ 353) was positively identified as 5-O-caffeoylquinic acid, yielding the base peak at $m / z 191$ and a secondary ion at $m / z 179$ with weak intensity ( $<5 \%$ base peak), characteristic of 5 -acylchlorogenic acids, as reported by Clifford, Johnston, Knight, \& Kuhnert
(2003). Peaks 3, 7, and $11\left([\mathrm{M}-\mathrm{H}]^{-}\right.$at $m / z$ 515) correspond to dicaffeoylquinic acids and were assigned to $1,3-\mathrm{O}-, \mathrm{1}, 5-\mathrm{O}$ - and 3,5-O-dicaffeoylquinic acids, respectively, based on their elution order and fragmentation patterns (Clifford et al., 2003; Clifford, Knight, \& Kuhnert, 2005). These type of mono and dicaffeoylquinic acid derivatives were also reported in samples of artichoke (Garbetta et al., 2014; Gouveia \& Castilho, 2012; Maietta et al., 2017; Pandino et al., 2011b,a; Petropoulos et al., 2016; Pistón et al., 2014; Ramos et al., 2014).

In general, the 'F1-25-4' genotype showed a more complex profile (15 individual phenolics) in comparison to ' $3 \mathrm{M}$ ' and ' $5 \mathrm{M}$ ', in which it was only possible to identify 11 individual compounds. Interestingly, this might indicate that genotype has higher influence on the phenolic composition than the inflorescence part (stigma, papillae, corolla or fibrous parts) itself. The detected differences were high enough to discriminate each analysed sample, as validated by the performed linear discriminant analysis. In fact, the three-dimensional plot resulting from combining the first three discriminant functions (Fig. 3a) was highly informative about the similarity among inflorescence parts belonging to the same genotype, as well as the dissimilarity among different genotypes. These three functions accounted for $97.8 \%$ of the observed variability (1st: $82.4 \%$, 2nd: $10.0 \%$, 3rd: $5.4 \%$ ). As easily observable, samples belonging to 'F1-25-4' were placed on the negative part of function 1 axis, while ' $3 \mathrm{M}$ ' and ' $5 \mathrm{M}$ ' are located on the positive side, highlighting the phenolic resemblance of these two genotypes (n.b., that both belong to the var. altilis). The compounds with highest contribution to this separation were those that could only be detected in 'F1-25-4', namely luteolin-O-hexoside-O-glucuronide, eriodictyol-Oglucuronide, 1,5-O-dicaffeoylquinic acid and 1,3-O-dicaffeoylquinic acid. On the other hand, the most significant differences among ' $3 \mathrm{M}$ ' and ' $5 \mathrm{M}$ ', which were respectively placed in the positive and negative 

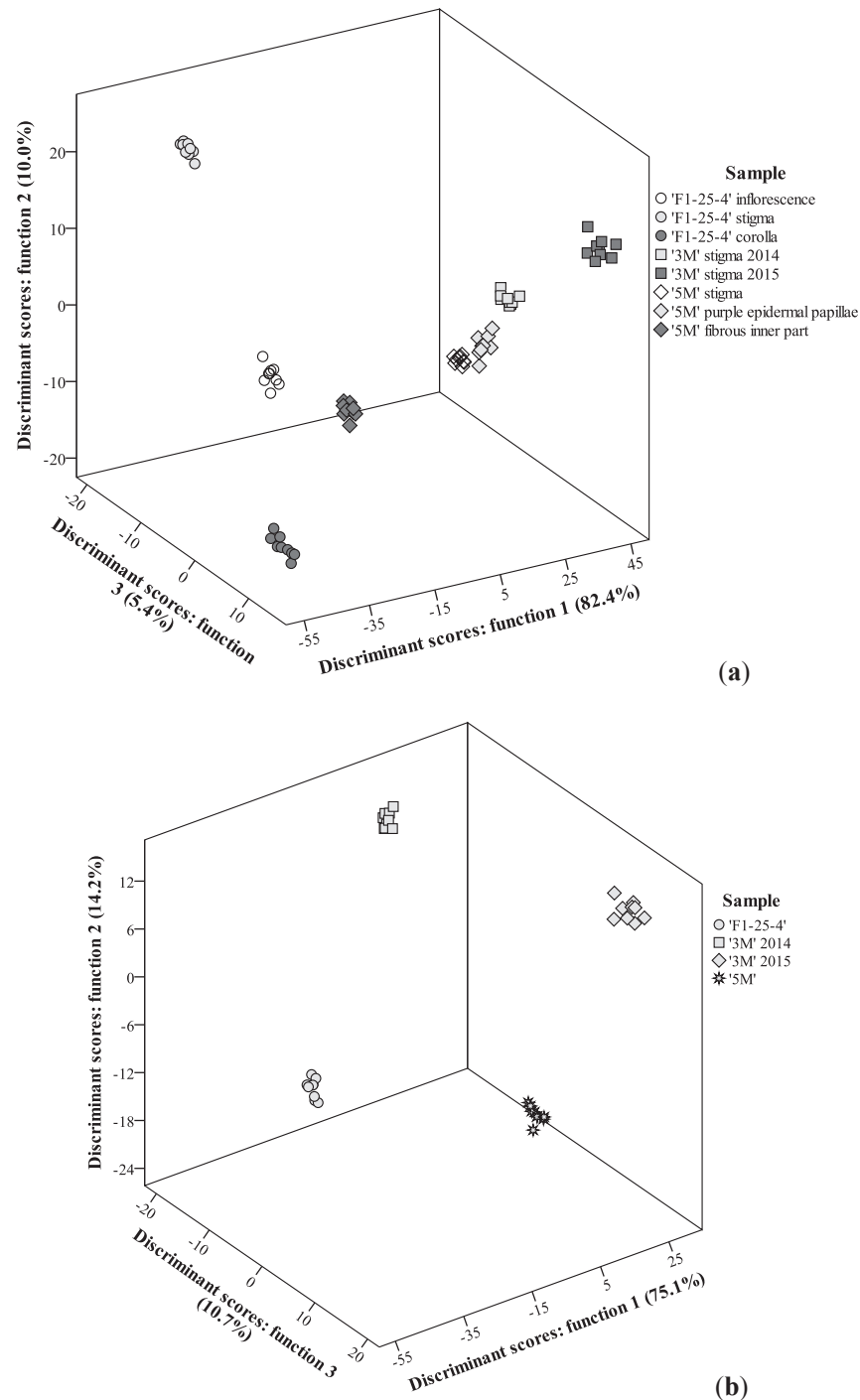

(b)

Fig. 3. Canonical discriminant functions coefficients defined from phenolic compounds profiles to assess their similarity among (a) different cardoon inflorescence tissues and (b) stigma from different genotypes.

sides of function 2 axis, were attributed to 3,5-O-dicaffeoylquinic acid (higher in ' $3 \mathrm{M}$ '), apigenin-7-O-rutinoside (higher in ' $3 \mathrm{M}$ ') and 3-Ocaffeoylquinic acid (higher in ' $5 \mathrm{M}$ '), the compounds more highly correlated with function 2 . Function 3 , on the contrary, did not show relevant effectiveness in separating markers corresponding to each genotype, demonstrating higher usefulness in discriminating different botanical tissues within each genotype (except for ' $3 \mathrm{M}$ ' for obvious reasons).

Despite the aforementioned differences, the most abundant phenolic compound in all samples (except $\mathrm{C} 1$, in which 5-O-caffeoylquinic acid was the major compound) was apigenin-7-O-glucuronide (Table 2). Pandino et al. (2011a,b) also described apigenin derivatives as the main phenolic compounds in hydromethanolic extracts of $C$. cardunculus. Similar results were obtained by Lombardo et al. (2010), who reported apigenin and caffeoylquinic acid derivatives as the major compounds in nine cultivars of artichoke from Italy. Pandino et al. (2013) also reported a very similar phenolic profile in leaves and floral stems of different clones of $C$. cardunculus var. scolymus, equally from Italy. On the other hand, Petropoulos et al. (2016) reported caffeoylquinic acid derivatives as the main compounds in hydromethanolic extracts of the head part of eight artichoke samples cultivated in Greece. Likewise, these authors reported higher contents of total phenolic compounds ( $163 \mathrm{mg} / \mathrm{g}$ extract), but lower values regarding flavonoids $(7.2 \mathrm{mg} / \mathrm{g}$ extract), which could be explained by the different geo-climatic conditions, and also by the different plant parts that were used. Ramos et al. (2014) reported mono and dicaffeoyloquinic acids as the major compounds in methanol/water/acetic acid extracts from several morphological parts of $C$. cardunculus L. var. altilis, followed by apigenin derivatives. The same authors reported higher contents of total phenolic compounds ( $\sim 70 \mathrm{mg} / \mathrm{g}$ of extract), which could be related to the different extraction solvent used, studied plant part, or different geographical origin.

Focussing the analysis in the stigma of the studied cardoon genotypes, it is evident that their phenolic profiles present significant differences. As easily observable from the LDA plot (Fig. 3b) markers corresponding to each group of samples were clearly individualized. The observed variability was divided by the three defined discriminant functions as follows: first, $75.1 \%$; second, $14.2 \%$ and third, $10.7 \%$. Among the included variables (all phenolic compounds and $\mathrm{EC}_{50}$ values for both antioxidant assays), those selected as being significantly discriminant were: 1,5-O-dicaffeoylquinic acid, 3-O-caffeoylquinic acid, grouped phenolic acids, reducing power, apigenin-8-O-rutinoside, DPPH scavenging activity, cyanidin-malonyl-hexoside and apigenin-7$O$-glucuronide. As may be observed in the three-dimensional plot, the main effect of function 1 was separating markers of 'F1-25-4' (negative end of the axis) from all the remaining samples. The variables with highest correlation with this function were 1,5-O-dicaffeoylquinic acid, which, in fact, could only be detected in 'F1-25-4', 3-O-caffeoylquinic acid and grouped phenolic acids, higher in 'F1-25-4' stigmas. Function 2 , on the other hand, had the main effect of individualizing markers corresponding to ' $5 \mathrm{M}$ ' stigma, mostly due to its lower content in apigenin-8-O-rutinoside and apigenin-7-O-glucuronide, the variables with highest correlation with this function. Lastly, ' 3 M' stigma from 2014 and 2015, had different coordinates only in what concerns function 3 , specifically due to the higher content of cyanidin-malonyl-hexoside and stronger reducing power observed in 2015 samples and the higher DPPH scavenging activity measured in 2014 ones. This observation indicates clearly that differences eventually induced by seasonality are less significant than those resulting from the intrinsic genotype influence. In either case, Lombardo et al. (2010) also detected some seasonal variability within hydromethanolic extracts of nine cultivars of artichoke.

\subsection{Bioactive properties}

In addition to their phenolic profile, the antioxidant and antibacterial activities of $C$. cardunculus samples were also studied (Table 3). In general, the whole inflorescence of 'F1-25-4' showed the highest bioactivity, either in regards to antioxidant effect or antimicrobial activity. Concerning the comparison among stigmas, 'F1-254' allowed better results than ' 3 M' and ' 5 M', which should be explained by the fact of its higher contents in phenolic acids, particularly in what concerns DPPH scavenging activity, which proved to be highly correlated $\left(r^{2}=0.919\right)$ with phenolic acid content. The $\mathrm{EC}_{50}$ values obtained for this assay are in general agreement with those reported in ethanolic (Kukić et al., 2008) and methanol/water/acetic acid (Ramos et al., 2014) extracts from different botanical parts of $C$. cardunculus.

Regarding antibacterial activity, the lowest MIC values were obtained for Gram-positive bacteria, mainly for Listeria monocytogenes, MSSA and MRSA, while the best results among Gram-negative bacteria 
Table 2

Phenolic compounds quantification ( $\mathrm{mg} / \mathrm{g}$ of extract) in the hydromethanolic extracts of Cynara cardunculus L. samples (mean \pm SD).

\begin{tabular}{|c|c|c|c|c|c|c|c|c|}
\hline & C1 & C2 & C3 & C4 & C5 & C6 & C7 & C8 \\
\hline \multicolumn{9}{|l|}{ Non-anthocyanin phenolic compounds } \\
\hline Gallic $\operatorname{acid}^{\mathrm{A}}$ & nd & nd & nd & $0.22 \pm 0.02$ & $0.17 \pm 0.01$ & $0.42 \pm 0.02$ & $0.35 \pm 0.03$ & $0.50 \pm 0.04$ \\
\hline 3-O-Caffeoylquinic acid ${ }^{\mathrm{B}}$ & $5.5 \pm 0.2$ & $7.6 \pm 0.2$ & $5.4 \pm 0.2$ & $1.3 \pm 0.1$ & $1.7 \pm 0.1$ & $1.8 \pm 0.1$ & $2.0 \pm 0.1$ & $2.0 \pm 0.2$ \\
\hline 1,3-O-Dicaffeoylquinic acid ${ }^{\mathrm{B}}$ & $2.4 \pm 0.1$ & $2.0 \pm 0.1$ & $1.7 \pm 0.1$ & nd & nd & nd & nd & nd \\
\hline 3-p-Coumarouylquinic acid ${ }^{\mathrm{C}}$ & $0.43 \pm 0.02$ & $0.66 \pm 0.05$ & $0.33 \pm 0.02$ & $0.69 \pm 0.05$ & $0.63 \pm 0.05$ & $0.52 \pm 0.04$ & $0.48 \pm 0.04$ & $0.55 \pm 0.05$ \\
\hline Luteolin-O-hexoside- $O$-glucuronide ${ }^{\mathrm{D}}$ & $1.05 \pm 0.05$ & $0.95 \pm 0.05$ & $0.85 \pm 0.05$ & nd & nd & nd & nd & nd \\
\hline Eriodictyol-O-glucuronide $^{\mathrm{E}}$ & $0.12 \pm 0.03$ & $\operatorname{tr}$ & $0.60 \pm 0.05$ & nd & nd & nd & nd & nd \\
\hline 1,5-O-Dicaffeoylquinic acid ${ }^{\mathrm{B}}$ & $0.75 \pm 0.05$ & $0.41 \pm 0.02$ & $0.67 \pm 0.05$ & nd & nd & nd & nd & nd \\
\hline Luteolin-7-O-rutinoside $^{\mathrm{D}}$ & $1.38 \pm 0.05$ & $0.97 \pm 0.05$ & $1.42 \pm 0.05$ & $1.0 \pm 0.05$ & $1.49 \pm 0.05$ & $0.99 \pm 0.04$ & $1.16 \pm 0.05$ & $0.81 \pm 0.04$ \\
\hline Luteolin-7-O-glucuronide $^{\mathrm{D}}$ & $2.6 \pm 0.1$ & $1.9 \pm 0.1$ & $2.2 \pm 0.1$ & $2.3 \pm 0.1$ & $3.2 \pm 0.2$ & $2.4 \pm 0.2$ & $2.6 \pm 0.1$ & $1.3 \pm 0.1$ \\
\hline Luteolin-7-O-glucoside $^{\mathrm{D}}$ & $2.2 \pm 0.1$ & $1.1 \pm 0.1$ & $2.2 \pm 0.2$ & $1.3 \pm 0.1$ & $1.6 \pm 0.1$ & $1.3 \pm 0.1$ & $1.4 \pm 0.1$ & $0.9 \pm 0.1$ \\
\hline 3,5-O-Dicaffeoylquinic acid ${ }^{\mathrm{B}}$ & $4.0 \pm 0.2$ & $5.8 \pm 0.2$ & $2.5 \pm 0.2$ & $1.1 \pm 0.1$ & $1.4 \pm 0.1$ & $0.9 \pm 0.1$ & $0.9 \pm 0.1$ & $0.9 \pm 0.1$ \\
\hline Apigenin-7-O-rutinoside ${ }^{\mathrm{D}}$ & $2.6 \pm 0.2$ & $4.1 \pm 0.2$ & $1.4 \pm 0.1$ & $6.0 \pm 0.2$ & $7.4 \pm 0.2$ & $3.8 \pm 0.1$ & $4.7 \pm 0.2$ & $2.1 \pm 0.2$ \\
\hline Apigenin-7-O-glucuronide ${ }^{\mathrm{D}}$ & $4.7 \pm 0.3$ & $7.7 \pm 0.2$ & $2.0 \pm 0.2$ & $8.1 \pm 0.2$ & $9.9 \pm 0.5$ & $6.6 \pm 0.3$ & $7.0 \pm 0.1$ & $3.4 \pm 0.2$ \\
\hline Luteolin-O-malonylhexoside ${ }^{\mathrm{D}}$ & $1.5 \pm 0.1$ & $1.5 \pm 0.1$ & $1.6 \pm 0.1$ & nd & nd & nd & nd & nd \\
\hline Apigenin-O-acetylhexoside ${ }^{\mathrm{D}}$ & $1.0 \pm 0.1$ & $1.2 \pm 0.1$ & $0.9 \pm 0.1$ & $1.6 \pm 0.1$ & $2.1 \pm 0.1$ & $1.6 \pm 0.1$ & $1.7 \pm 0.1$ & $1.1 \pm 0.1$ \\
\hline \multicolumn{9}{|l|}{ Anthocyanin phenolic compounds } \\
\hline Cyanidin-malonyl-hexoside ${ }^{\mathrm{F}}$ & $0.44 \pm 0.02$ & $0.74 \pm 0.05$ & $0.55 \pm 0.05$ & $1.2 \pm 0.1$ & $2.0 \pm 0.1$ & $1.2 \pm 0.1$ & $1.2 \pm 0.1$ & $0.8 \pm 0.1$ \\
\hline Total phenolic acids & $13.0 \pm 0.4$ & $16.4 \pm 0.5$ & $10.6 \pm 0.4$ & $3.3 \pm 0.2$ & $3.9 \pm 0.3$ & $3.6 \pm 0.2$ & $3.6 \pm 0.1$ & $4.0 \pm 0.3$ \\
\hline Total non-anthocyanin flavonoids & $17 \pm 1$ & $19 \pm 1$ & $13 \pm 1$ & $20 \pm 1$ & $26 \pm 1$ & $16.7 \pm 0.5$ & $18.6 \pm 0.3$ & $9.6 \pm 0.3$ \\
\hline Total phenolic compounds & $31 \pm 1$ & $37 \pm 1$ & $24 \pm 1$ & $25 \pm 1$ & $31 \pm 1$ & $22 \pm 1$ & $24 \pm 1$ & $14 \pm 1$ \\
\hline
\end{tabular}

tr: trace amounts; nd: not detected. Standard calibration curves: (A) gallic acid ( $\left.y=214168 x+27102, R^{2}=0.9999\right)$; (B) chlorogenic acid ( $y=168823 x-161172$, $\left.R^{2}=0.999\right)$; (C) $p$-coumaric acid $\left(y=301950 x+6966.7, R^{2}=0.999\right)$; (D) apigenin-7-O-glucoside $\left(\mathrm{y}=10683 \mathrm{x}-45794, R^{2}=0.991\right)$; (E) naringenin $\left(y=18433 x+78903, R^{2}=0.9998\right)$; (F) Cyanidin-3-O-glucoside $\left(y=243287 x-1 \mathrm{E} 6, R^{2}=0.9953\right)$.

Table 3

Antioxidant and antimicrobial activities of the hydromethanolic extracts of Cynara cardunculus L. samples (mean \pm SD).

\begin{tabular}{|c|c|c|c|c|c|c|c|c|}
\hline & C1 & C2 & C3 & C4 & C5 & C6 & C7 & C8 \\
\hline \multicolumn{9}{|c|}{ Antioxidant activity, $E C_{50}$ values $(\mathrm{mg} / \mathrm{ml})$} \\
\hline DPPH scavenging activity & $0.16 \pm 0.01$ & $0.29 \pm 0.01$ & $0.45 \pm 0.01$ & $1.35 \pm 0.05$ & $1.06 \pm 0.02$ & $1.47 \pm 0.04$ & $1.48 \pm 0.04$ & $1.71 \pm 0.05$ \\
\hline Reducing power & $0.34 \pm 0.01$ & $0.34 \pm 0.01$ & $0.42 \pm 0.01$ & $0.57 \pm 0.01$ & $1.04 \pm 0.03$ & $0.96 \pm 0.02$ & $0.92 \pm 0.02$ & $0.31 \pm 0.01$ \\
\hline \multicolumn{9}{|c|}{$\begin{array}{l}\text { Antimicrobial activity, MIC values }(\mathrm{mg} / \mathrm{ml}) \\
\text { Gram-negative bacteria }\end{array}$} \\
\hline Escherichia coli ESBL & 20 & 20 & 20 & $>20$ & $>20$ & $>20$ & $>20$ & $>20$ \\
\hline Escherichia coli & 20 & 20 & 20 & $>20$ & $>20$ & $>20$ & $>20$ & $>20$ \\
\hline Klebsiella pneumoniae & 20 & 20 & 20 & $>20$ & $>20$ & $>20$ & $>20$ & $>20$ \\
\hline Klebsiella pneumoniae ESBL & 20 & 20 & 20 & $>20$ & $>20$ & $>20$ & $>20$ & $>20$ \\
\hline Morganella morganii & 10 & $>20$ & $>20$ & $>20$ & $>20$ & 20 & $>20$ & 10 \\
\hline Pseudomonas aeruginosa & 20 & 20 & $>20$ & 20 & 20 & 10 & 20 & $>20$ \\
\hline \multicolumn{9}{|l|}{ Gram-positive bacteria } \\
\hline Enterococcus faecalis & 10 & 10 & 10 & 20 & 20 & 10 & 10 & 10 \\
\hline Listeria monocytogenes & 2.5 & 10 & 10 & 2.5 & 5 & 10 & 5 & 10 \\
\hline MRSA & 10 & 20 & 10 & 20 & 20 & $>20$ & $>20$ & 10 \\
\hline MSSA & 5 & $>20$ & 10 & 10 & 10 & $>20$ & $>20$ & 10 \\
\hline
\end{tabular}

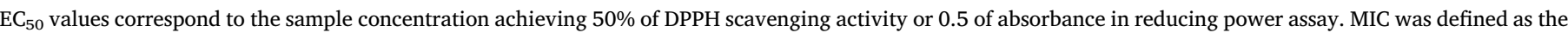

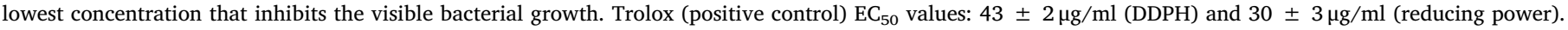

were observed for Morganella morganii and Pseudomonas aeruginosa. In line with the antioxidant activity assays, the best results pertaining to Gram-positive bacteria were obtained with the inflorescence extracts of 'F1-25-4' (C1). Nevertheless, the activity against Gram-negative bacteria was similar for all cardoon samples.

In general, the MIC values were higher than those reported by Kukić et al. (2008) in alcoholic and aqueous preparations of artichoke; however, the bacteria strains used in that study belong to ATCC (with no resistance profile against antibiotics).

\section{Conclusion}

Generally, apigenin and caffeoylquinic acid derivatives were the major phenolic compounds found in the studied samples, but 'F1-25-4' stood out as the genotype with highest content of phenolic compounds. Likewise, 'F1-25-4' stigma showed the highest DPPH scavenging activity. Accordingly, this genotype stood out as the best option (among the studied ones) as a source of an added-value standardized ingredient (stigma) for PDO cheese production. Complementarily, other botanical parts of cardoon (C1, C3, C7 and C8) showed good levels of phenolic compounds and bioactivity, raising the possibility of their use as sources of bioactive compounds with application in food and pharmaceutical industries, therefore adding value to those otherwise discarded vegetal materials.

\section{Acknowledgements}

The authors are grateful to the Foundation for Science and 
Technology (FCT, Portugal) and FEDER under Programme PT2020 for financial support to CIMO (UID/AGR/00690/2013), L. Barros and J. Barreira contracts. The authors are grateful to the FEDER-Interreg España-Portugal programme for financial support through the project 0377_Iberphenol_6_E.

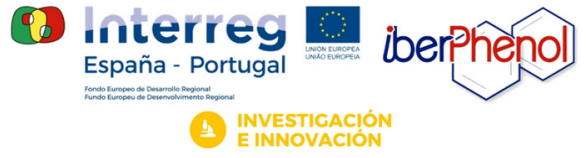

\section{References}

Barracosa, P., Oliveira, J., Barros, M., \& Pires, E. (2018). Morphological evaluation of cardoon (Cynara cardunculus L.): Assessing biodiversity for applications based on tradition, innovation and sustainability. Genetic Resources and Crop Evolution, 65(1), 17-28. http://dx.doi.org/10.1007/s10722-017-0579-0.

Barros, L., Pereira, E., Calhelha, R. C., Dueñas, M., Carvalho, A. M., Santos-Buelga, C., \& Ferreira, I. C. F. R. (2013). Bioactivity and chemical characterization in hydrophilic and lipophilic compounds of Chenopodium ambrosioides L. Journal of Functional Foods, 5(4), 1732-1740. http://dx.doi.org/10.1016/j.jff.2013.07.019.

Basnizki, J., \& Zohary, D. (1994). Breeding of seed-planted artichoke. In Jules Janick (Ed.). Plant Breeding reviews (pp. 253-267). John Wiley \& Sons.

Bessada, S. M. F., Barreira, J. C. M., Barros, L., Ferreira, I. C. F. R., \& Oliveira, M. B. P. P. (2016). Phenolic profile and antioxidant activity of Coleostephus myconis (L.) Rchb. f.: An underexploited and highly disseminated species. Industrial Crops \& Products, 89, 45-51. http://dx.doi.org/10.1016/j.indcrop.2016.04.065.

Clifford, M. N., Johnston, K. L., Knight, S., \& Kuhnert, N. (2003). Hierarchical scheme for LC-MSn identification of chlorogenic acids. Journal of Agricultural and Food Chemistry, 51(10), 2900-2911. http://dx.doi.org/10.1021/jf026187q.

Clifford, M. N., Knight, S., \& Kuhnert, N. (2005). Discriminating between the six isomers of dicaffeoylquinic acid by LC-MSn. Journal of Agricultural and Food Chemistry, 53(10), 3821-3832. http://dx.doi.org/10.1021/jf050046h.

Colantuono, A., Ferracane, R., \& Vitaglione, P. (2018). Potential bioaccessibility and functionality of polyphenols and cynaropicrin from breads enriched with artichoke stem. Food Chemistry, 245, 838-844. http://dx.doi.org/10.1016/j.foodchem.2017.11 099.

Dias, M. I., Barros, L., Dueñas, M., Pereira, E., Carvalho, A. M., Alves, R. C., ... Ferreira, I. C. F. R. (2013). Chemical composition of wild and commercial Achillea millefolium L. and bioactivity of the methanolic extract, infusion and decoction. Food Chemistry, 141(4), 4152-4160. http://dx.doi.org/10.1016/j.foodchem.2013.07.018.

Dias, M. I., Barros, L., Morales, P., Cámara, M., Alves, M.-J., Oliveira, M. B. P., ... Ferreira, I. C. F. R. (2016). Wild Fragaria vesca L. fruits: a rich source of bioactive phytochemicals. Food \& Function, 4523-4532. http://dx.doi.org/10.1039/c6fo01042c.

Fratianni, F., Tucci, M., Palma, M. D., Pepe, R., \& Nazzaro, F. (2007). Polyphenolic composition in different parts of some cultivars of globe artichoke (Cynara cardunculus L. var. scolymus (L.) Fiori). Food Chemistry, 104(3), 1282-1286. http://dx.doi. org/10.1016/j.foodchem.2007.01.044.

Garbetta, A., Capotorto, I., Cardinali, A., D’Antuono, I., Linsalata, V., Pizzi, F., \& Minervini, F. (2014). Antioxidant activity induced by main polyphenols present in edible artichoke heads: Influence of in vitro gastro-intestinal digestion. Journal of Functional Foods, 10, 456-464. http://dx.doi.org/10.1016/j.jff.2014.07.019.

Gonçalves, G. A., Soares, A. A., Correa, R. C. G., Barros, L., Haminiuk, C. W. I., Peralta, R. M., ... Bracht, A. (2017). Merlot grape pomace hydroalcoholic extract improves the oxidative and inflammatory states of rats with adjuvant-induced arthritis. Journal of Functional Foods, 33, 408-418. http://dx.doi.org/10.1016/j.jff.2017.04.009.

Gouveia, S. C., \& Castilho, P. C. (2012). Phenolic composition and antioxidant capacity of cultivated artichoke, Madeira cardoon and artichoke-based dietary supplements. Food Research International, 48(2), 712-724. http://dx.doi.org/10.1016/j.foodres. 2012.05.029.

Kuete, V., Ango, P. Y., Fotso, G. W., Kapche, G. D. W. F., Dzoyem, J. P., Wouking, A. G., ... Abegaz, B. M. (2011a). Antimicrobial activities of the methanol extract and compounds from Artocarpus communis (Moraceae). BMC Complementary and Alternative Medicine, 11(1), 42. http://dx.doi.org/10.1186/1472-6882-11-42.

Kuete, V., Justin, K., Louis, P. S., Bathelemy, N., Herve, M. P. P., Pantaleon, A., \& Bonaventure, T. N. (2011b). Antimicrobial activities of the methanol extract, fractions and compounds from Ficus polita Vahl. (Moraceae). BMC Complementary and Alternative Medicine, 11, 6 .

Kukić, J., Popović, V., Petrović, S., Mucaji, P., Ćirić, A., Stojković, D., \& Soković, M. (2008). Antioxidant and antimicrobial activity of Cynara cardunculus extracts. Food
Chemistry, 107(2), 861-868. http://dx.doi.org/10.1016/j.foodchem.2007.09.005.

attanzio, V., Kroon, P. A., Linsalata, V., \& Cardinali, A. (2009). Globe artichoke: A functional food and source of nutraceutical ingredients. Journal of Functional Foods, 1(2), 131-144. http://dx.doi.org/10.1016/j.jff.2009.01.002.

Lombardo, S., Pandino, G., Mauromicale, G., Knödler, M., Carle, R., \& Schieber, A. (2010). Influence of genotype, harvest time and plant part on polyphenolic composition of globe artichoke [Cynara cardunculus L. var. scolymus (L.) Fiori]. Food Chemistry, 119(3), 1175-1181. http://dx.doi.org/10.1016/j.foodchem.2009.08.033.

Maietta, M., Colombo, R., Lavecchia, R., Sorrenti, M., Zuorro, A., \& Papetti, A. (2017). Artichoke (Cynara cardunculus L. var. scolymus) waste as a natural source of carbonyl trapping and antiglycative agents. Food Research International, 100(June), 780-790. http://dx.doi.org/10.1016/j.foodres.2017.08.007.

Nouraei, S., Rahimmalek, M., \& Saeidi, G. (2018). Variation in polyphenolic composition, antioxidants and physiological characteristics of globe artichoke (Cynara cardunculus var. scolymus Hayek L.) as affected by drought stress. Scientia Horticulturae, 233, 378-385. http://dx.doi.org/10.1016/j.scienta.2017.12.060.

Pandino, G., Lombardo, S., \& Mauromicale, G. (2013). Globe artichoke leaves and floral stems as a source of bioactive compounds. Industrial Crops and Products, 44, 44-49. http://dx.doi.org/10.1016/j.indcrop.2012.10.022.

Pandino, G., Lombardo, S., Mauromicale, G., \& Williamson, G. (2011a). Phenolic acids and flavonoids in leaf and floral stem of cultivated and wild Cynara cardunculus L. genotypes. Food Chemistry, 126(2), 417-422. http://dx.doi.org/10.1016/j.foodchem. 2010.11.001.

Pandino, G., Lombardo, S., Mauromicale, G., \& Williamson, G. (2011b). Profile of polyphenols and phenolic acids in bracts and receptacles of globe artichoke (Cynara cardunculus var. scolymus) germplasm. Journal of Food Composition and Analysis, 24(2), 148-153. http://dx.doi.org/10.1016/j.jfca.2010.04.010.

Pereira, E., Barros, L., Antonio, A. L., Cabo Verde, S., Santos-Buelga, C., \& Ferreira, I. C. F. R. (2016). Infusions from Thymus vulgaris L. treated at different gamma radiation doses: Effects on antioxidant activity and phenolic composition. LWT - Food Science and Technology, 74, 34-39. http://dx.doi.org/10.1016/j.lwt.2016.07.027.

Pereira, C., Barros, L., Carvalho, A. M., Santos-Buelga, C., \& Ferreira, I. C. R. F. (2015). Infusions of artichoke and milk thistle represent a good source of phenolic acids and flavonoids. Food and Function, 6(1), 55-61. http://dx.doi.org/10.1039/C4FO00834K.

Petropoulos, S. A., Pereira, C., Barros, L., \& Ferreira, I. C. F. R. (2017). Leaf parts from Greek artichoke genotypes as a good source of bioactive compounds and antioxidants. Food and Function, 8(5), 2022-2029. http://dx.doi.org/10.1039/ C7FO00356K.

Petropoulos, S. A., Pereira, C., Ntatsi, G., Danalatos, N., Barros, L., \& Ferreira, I. C. F. R. (2016). Nutritional value and chemical composition of Greek artichoke genotypes. Food Chemistry. http://dx.doi.org/10.1016/j.foodchem.2017.01.159.

Pistón, M., Machado, I., Branco, C. S., Cesio, V., Heinzen, H., Ribeiro, D., ... Freitas, M. (2014). Infusion, decoction and hydroalcoholic extracts of leaves from artichoke (Cynara cardunculus L. subsp. cardunculus) are effective scavengers of physiologically relevant ROS and RNS. Food Research International, 64, 150-156. http://dx.doi.org/ 10.1016/j.foodres.2014.05.078.

Portis, E., Barchi, L., Acquadro, A., Macua, J. I., \& Lanteri, S. (2005). Genetic diversity assessment in cultivated cardoon by AFLP (amplified fragment length polymorphism) and microsatellite markers. Plant Breeding, 124(3), 299-304. http://dx.doi.org/10. 1111/j.1439-0523.2005.01098.x.

Ramos, P. A. B., Santos, S. A. O., Guerra, Â. R., Guerreiro, O., Freire, C. S. R., Rocha, S. M., ... Silvestre, A. J. D. (2014). Phenolic composition and antioxidant activity of different morphological parts of Cynara cardunculus L. var. altilis (DC). Industrial Crops and Products, 61, 460-471. http://dx.doi.org/10.1016/j.indcrop.2014.07.042.

Rodriguez, T. S., Giménez, D. G., \& Vázquez, R. P. (2002). Choleretic activity and biliary elimination of lipids and bile acids induced by an artichoke leaf extract in rats. Phytomedicine, 9(8), 687-693. http://dx.doi.org/10.1078/094471102321621278.

Roseiro, L. B., Viala, D., Besle, J. M., Carnat, A., Fraisse, D., Chezal, J. M., \& Lamaison, J. L. (2005). Preliminary observations of flavonoid glycosides from the vegetable coagulant Cynara L. in protected designation of origin cheeses. International Dairy Journal (pp. 579-584). Elsevier. http://dx.doi.org/10.1016/j.idairyj.2004.07.027.

Scaglione, D., Acquadro, A., Portis, E., Taylor, C. A., Lanteri, S., \& Knapp, S. J. (2009). Ontology and diversity of transcript-associated microsatellites mined from a globe artichoke EST database. BMC Genomics, 10(1), 454. http://dx.doi.org/10.1186/1471 2164-10-454.

Valentão, P., Fernandes, E., Carvalho, F., Andrade, P. B., Seabra, R. M., \& Bastos, M. L. (2002). Antioxidative properties of cardoon (Cynara cardunculus L.) infusion against superoxide radical, hydroxyl radical, and hypochlorous acid. Journal of Agricultural and Food Chemistry, 50(17), 4989-4993. http://dx.doi.org/10.1021/jf020225o.

Veríssimo, P., Esteves, C., Faro, C., \& Pires, E. (1995). The vegetable rennet of Cynara cardunculus L. contains two proteinases with chymosin and pepsin-like specificities. Biotechnology Letters, 17(6), 621-626. http://dx.doi.org/10.1007/BF00129389. 